\title{
Viewpoint: Indigenous knowledge systems and environmental social work education: Towards environmental sustainability
}

\author{
Mogomme Alpheus Masoga, University of Zululand, \\ and Allucia Lulu Shokane, University of Venda, South Africa
}

\begin{abstract}
Prior to colonisation, most indigenous communities were using indigenous knowledge systems (IKS) as part of their livelihood. The livelihoods of rural and indigenous peoples and those living in poverty are often closely tied to the use of biodiversity. Positive action, if taken in these communities, could decrease pressure from climate change impacts. Indigenous knowledge can be a sustainable development and livelihood tool that can be used throughout the Global South. The key research question explored in this paper is: Which IKS applied by marginalised communities can be used by environmental education and social workers to advance environmental sustainability? Afro-sensed and sustainable livelihood approaches have been adopted to guide the theoretical framework. The qualitative research methodology followed a descriptive and explorative design. The research findings concluded that the integration of IKS in social work and environmental education can contribute to environmental sustainability efforts. Finally, a recommendation is made on how social sciences and educational practitioners can work with marginalised communities to adapt IKS.
\end{abstract}

Key words: indigenous knowledge systems, social work, environmental sustainability, livelihoods.

\section{Introduction}

Indigenous knowledge systems (IKS) are observed as interrelated to the continued existence of communities in general or specific fields, such as in the protection and use of the local environment and enhancing food security (Masoga, 2017). The importance of mainstreaming IKS for the realisation of human rights, sustainable development, poverty eradication and disaster reduction has been recognised in a series of international instruments such as the United Nations (UN) Declaration on the Rights of Indigenous Peoples, the Ahmadabad Framework on Environmental Education, the UN Declaration on Human Rights, the UN Covenant on Civil and Political Human Rights, and the UN Covenant on Economic, Social and Cultural Rights. The UN Declaration on the Rights of Indigenous Peoples (2007) acknowledges the importance of indigenous knowledge, cultures and traditional practices for sustainable and equitable development and proper management of the environment. In this context, our understanding of the environment is based on the work of Mokuku and Janse van Rensburg, which summarises the environment as 'a dynamic web of interconnected biophysical, economic, political and socio-cultural contexts in which people are involved' (1997:32). Consequently, we argue that indigenous knowledge is not widely accepted as a significant factor in the development of marginalised communities. 
Mokuku and Janse van Rensburg (1997:31) maintain that 'the political dimension of the environment web requires that some environmental problems be traced to the colonial rule' and criticise the dominant imported knowledge systems for their silence in defending the exploitation of local communities and the whole of the environment. Prior to colonisation, communities throughout the Global South had been using IKS as part of their livelihood (Masoga \& Shokane, 2018). The legacy of apartheid failed to acknowledge people's IKS and the environment (Mokuku \& Janse van Rensburg, 1997; Mwansa, 2011, 2015; Prah, 2016). Magoro and Masoga (2005) attest that the system of apartheid in South Africa left many people poor, desolate, jobless and without proper education. Though not all aspects of western knowledge systems have been devastating, their dominance over African IKS has had disturbing effects on the current education system in Africa, including in South Africa. As a consequence, Prah (2016) notes that the colonial and apartheid educational systems created not only a sense of disaffection with, or a desire to dissociate from, the native heritage, but also affected the individual's sense of self-confidence. Mwansa (2011) further affirms that the effects of colonialism and apartheid are still visible in South Africa and are manifested in various social issues such as poverty, disease and hopelessness. This is pertinent to the practice of social work, which holds out a promise to restore the dignity of millions of South African people, which has been lost because of colonial and apartheid history (Mwansa, 2011).

The United Nations Development Programme (UNDP, 2007) declared that the historic marginalised and colonised countries - with limited access to resources, restricted rights and no voice in decision-making - are extremely vulnerable to environmental impacts. Kalu (2008) contends that scholarly research and discussion around the colonial and postcolonial situations have often ignored the dynamic process of African peoples' estrangement from their heritage. Mokuku and Janse van Rensburg have noted (1997:34) that local knowledge and heritage were also often ignored by indigenous peoples themselves, as well as curriculum developers 'in a predominant reliance on imported knowledge systems from external "experts" for development'. It is against this backdrop that the research objective was formulated to explore how marginalised communities apply IKS towards maintaining their livelihoods, and whether this can be used for sustainability efforts in the context of what we would call environmental social work.

In recent years, decision-makers in programmes and policy development addressing environmental challenges such as climate change have acknowledged that they lack knowledge about the links between social work and indigenous knowledge. It is essential to comprehend the connotations of both concepts. Social work can be understood as 'a practice-based profession [...] underpinned by theories of social work, social sciences, humanities and indigenous knowledge, [which] engages people and structures to address life challenges and enhance wellbeing' (IFSW, IASSW \& ICSW, 2012:1). Indigenous knowledge is known to be local and generated within communities (Masoga, 2017). Shava and Manyike (2018:36) further differentiate indigenous knowledge as 'transgenerational, transmitted from generation to generation orally (through narratives, stories/folklore, songs and poetry), visually (through arts, such as "bushmen" paintings, writings, craft, cultural rituals and dance), practically (through doing and the artefacts associated with practice) and spiritually (through dreams and visions 
from the ancestors)'. In addition, Masoga (2017) emphasises that IKS emanate from the human spirit and life experiences organised and ordered into accumulated knowledge with the objective of utilising it for quality of life and to create a liveable environment for both human and other forms of life. Shava and Manyike (2018), as well as Masoga (2017) and Shava (2013), consider the main features of indigenous knowledge to include people, space and context, culture, language, knowledge and practices that are dynamic. Furthermore, the aforesaid authors cogitate that IKS should be based on innovation, adaptation and experimentation. Subsequently, Shava, Zazu, Tidball and O’Donoghue, (2009:218) affirm that indigenous knowledge can be utilised as 'a resource for community sustenance in contexts of environmental risk, vulnerability and uncertainty through education processes within local contexts'. Against this backdrop, it is contended that working with IKS and environmental social work education will determine the form and content of the African development strategy: to ensure that developmental change on the continent should accommodate itself to the values, interests, aspirations and/or institutions that are important to African people's lives. In principle, 'environmental education should encompass the development of environmental awareness, knowledge, values, responsibility and action' (Reddy, 2017).

\section{Environmental social work education and IKS}

The expiration of the Millennium Development Goals (MDGs) in 2015 opened the opportunity for new global road maps for pursuing development priorities. This was evident in the UN and its member countries agreeing to address environmental sustainability and related global inequities through the signing of the Sustainable Development Goals (SDGs). Any country that is a member of the UN is also engaged by the UN Development Policy to raise views, share practical experiences and to make recommendations in respect of the SDGs.

This paper was also motivated by the Global Agenda for Social Work and Social Development's commitment to action toward environmental sustainability as one of the four pillars of Global Agenda (Jones \& Truell, 2012; Rinkel \& Powers, 2018). Recognising that past and present political, economic, cultural and social orders, shaped in specific contexts, have had unequal consequences for global, national and local communities and have negative impacts on marginalised people, the four pillars of the Global Agenda (Jones \& Truell, 2012) were developed as follows:

- Promoting social and economic equalities;

- Promoting the dignity and worth of peoples;

- Working toward environmental sustainability; and

- Strengthening recognition of the importance of human relationships.

Noting that 'across the globe, evidence abounds that environment is in a crisis', Rinkel and Powers (2018:16) call on social and humanities professionals to focus their research energies on environmental sustainability as part of their contribution to the Global Agenda. We call on these professionals, including environmental education specialists and social workers, to value 
traditional knowledge and innovations as part of their engagement with their communities. These could safeguard communities with respect to inclusion, sustainability and fulfilment (IFSW, IASSW \& ICSW, 2012).

Shokane (2016:104) maintains that 'the effects of climate change affect everyone, but disproportionately the most vulnerable population which includes the young, the old, those with chronic illnesses, and the poor and people living with disabilities, which the social work profession mostly caters for'. Thus, environmental issues impact not only the socio-political, economic and physical environment in which social workers are engaged, but also the type of work social workers will be called upon to carry out (Dominelli, 2012; Gray, Coates \& Hetherington, 2013).

\section{Problem statement}

Though there is emerging literature on environmental social work education (Dominelli, 2011, 2012; Gray, Coates \& Hetherington, 2013; Lysack, 2008; Shokane \& Nel, 2017), there has been little engagement with IKS and how marginalised communities can work towards environmental sustainability (Masoga \& Shokane, 2018). Thus, the researchers were challenged to conduct research that combines the fields of environmental education, social work education as well as indigenous knowledge, and focuses on how they can be integrated to address the needs of communities and how to engage with them effectively in working towards sustainability. The main research question explored in this paper is: Which IKS applied by marginalised communities can be used by environmental education and social workers to advance environmental sustainability?

\section{Theoretical lens}

In implementing this research, an African philosophical lens was applied. Africa is encouraged to move away from models that rely only on western frameworks and philosophies and move towards Afrocentric models based on indigenous knowledge systems, community-based interventions and local values and practices (Mwansa, 2010). Asante (1998:2) considers African philosophy to 'place African ideas at the centre of any analysis that involves African culture and behaviour'. In the context of this paper, the Afro-sensed theory described by Masoga and Shokane (2018) has been championed for its focus on indigenous knowledges and cultural approaches used to discover unique indigenous ways of dealing with environmental issues. This theory was developed by Masoga (2017) with the intention of guiding practitioners to mitigate against climate change impacts utilising IKS in a local, culturally appropriate and sensitive manner.

In addition to the Afro-sensed theory, the sustainable livelihood perspective (Chambers \& Conway, 1992) was integrated for its value in assisting indigenous communities to remain sustainable utilising their IKS. The sustainable livelihood perspective focuses on both the assets and strengths (which would include IKS) as well as the vulnerability of people in coping with hardship and maintaining the IKS they have preserved. The composite definition of a 
sustainable rural livelihood is applied at the community level to comprise 'the capabilities, assets (stores, resources, claims and access) and activities required for a means of living and its ability to provide opportunities for the next generation' (Chambers \& Conway, 1992:7-8). It is worth emphasising that IKS involve assets and capabilities that can be used to improve the livelihood of the people. Since indigenous communities will be (and are) affected by global issues like climate change, their needs and interests need to be reflected at the community, national and international level.

\section{Methodology}

A qualitative research methodology was used which followed a descriptive and explorative design (Babbie \& Mouton, 2001) and focused on IKS generated and recognised in the community as relating to environmental sustainability. This paper draws from data collected between August and October 2017 in the Ga-Sekororo villages of the Maruleng sub-district in Mopani District, Limpopo Province, South Africa.

Twenty key persons in the community (elders, parents, local authority representatives and community professionals such as farmers and traditional healers) were purposely selected for their deep insight on the topic under review to participate in a focus group discussion. Ethical clearance to conduct this study was obtained from the University of Venda Research and Publications Committee. Informed, written consent was obtained in advance from all research participants.

Field notes and an audio-recorder were used to record the oral data, which was later transcribed from Sepedi into English. Attention was paid to narratives or stories since they provide a cultural lens. Qualitative content analysis was used as 'a research method for the subjective interpretation of the content of text data through the systematic classification process of coding and identifying themes or patterns' (Hsieh \& Shannon, 2005:1277). The content analysis involved a description of the IKS as described by the custodians of the IKS themselves. Of importance was the custodians' understanding of the meaning of their knowledge. What then followed was the interpretation of the underlying context. Issues of rigour and trustworthiness in conducting IKS research were addressed to ascertain the 'authenticity' of the findings (Zuber-Skerrit \& Fletcher, 2007:423), that is, that the research results are valid and reliable if they are recognisable and authentic to the people involved in the research, even if not necessarily to others.

\section{Findings}

The findings are based on the three themes that emerged during the analysis of the data produced during the focus group discussion with indigenous knowledge holders, namely:

1. The lack of recognition in environmental sustainability efforts of indigenous knowledge holders;

2. The use of natural resources through IKS; and

3. IKS and the knowledge of indigenous plants. 


\section{Theme 1: The lack of recognition in environmental sustainability efforts of indigenous knowledge holders}

The community members participating in the focus group discussion expressed a concern about their lack of recognition in environmental sustainability efforts. They narrated how they felt undermined by the government as they are not involved in environmental sustainability efforts in their community. In agreement, the participants expressed the following view: ' $G a$ re akaretšwe go diphetho tše di dirwago mabapi le phetogo ya leratadima le thokomelo ya tikologo mo setšhabeng' [They are excluded in the decision-making regarding climate change and environmental sustainability].

The participants went on to say: 'Tsebo ya sekgale goba segologolo ga e tšeelwe hlogong' [Their traditional indigenous knowledge is undermined in their community]. The participants specifically emphasised that the government was responsible for not recognising their IKS: 'Mmušo ga o tšeele hlogong tsebo ya segologolo le šetšo ge ba tšea diphetho tša bona' [The government does not recognise their traditions, knowledge and culture in their decision-making].

\section{Theme 2: The use of natural resources through IKS}

The findings indicate that most people in the indigenous community of Ga-Sekororo depend greatly on the diversity of natural resources. The theme of utilisation of natural resources through IKS emerged as three sub-themes, namely, the preservation of food, water and energy.

\section{Preservation of food}

The participants reflected that their livelihood in terms of their food needs depends on IKS as follows: 'Re bjala dibjalo tše di kgotlelelago mabaka a komelelo' [They only plant crops that are tolerant to drought]. They indicated that they can produce a variety of plants and crops but had to focus on those tolerant of high temperatures. The community uses their knowledge of drought-resistant crops to adapt to environmental hazards which affect food security and water management in rural areas. By allowing them to adapt their farming practices to climatic conditions, indigenous knowledge provides social security and environmental sustainability.

Moreover, the participants noted that: 'Re buna dibjalwa tša go swana le merogo, dimake, ditloo, mapampune le mafela' [They harvest crops and grow traditional vegetables (morogo), leafy vegetables, groundnuts, pumpkins and mealies]. In similar research, Shava (1999: 85) affirmed that indigenous food plants have in the past played an important role in the diet of African communities.

Additionally, the participants also supported their livelihoods with indigenous knowledge about food production: 'Re iphediša ka dimela goba dibjalwa' - which suggests that they use the crops for household consumption and income generation. Muchenje and Goronga (2015) note that production techniques based on IKS tend to ensure food security at the household level.

\section{Preservation of water}

The focus group participants indicated that their main challenge was the lack of clean and running water. They explained that they drink from the river - 'Re nwa meetse a go tšwa dinokeng' and: 'Re ikanntše meetse a pula e bile re a šomišstšsa go nošetša dibjalwa le ge e le gore matšatši a lehono 
pula ga e sana gabotse' - which implies that they depend on rain to water their crops, 'though it does not rain often'. Drought, desertification, and erratic rainfall are challenges that will worsen with climate change. In a similar study, O’Donoghue, Shava and Zazu (2014) identified innovative indigenous practices for water conservation reflecting indigenous peoples' capacity to manage their local environment and to adapt to its related climatic changes.

\section{Preservation of energy}

The participants indicated that they still largely have to secure energy for cooking and heating through indigenous ways: 'Re ithekgile go di dirišwa tša hlago bjalo ka dikgong re apea dijo le go difuthumatš maregeng' [They depend on natural resources such as firewood to cook food, boil water and keep warm in winter]. Firewood is their main energy source, although the cutting of trees for firewood exposes them to possible prosecution, fines and imprisonment: 'Bahlokomedi ba hlago ba a re golega ge ba re hwetša re rema dihlare' [The rangers arrest them when the find them cutting trees].

The findings reveal an indigenous community collecting natural resources for fuel to a point where it has to be controlled by law. Elsewhere in the Global South, communities also use natural resources as food, medicine or fodder for their animals. The loss of, or reduction in, these resources will negatively impact their livelihoods. Without secure access to, and control over, natural resources (land, water, livestock, trees), the participants felt vulnerable, and linked these feelings to access to, or ownership of, farmland, as follows: 'Ga re kgone go hwetša lefase'. In this context, 'vulnerability can be regarded as the degree to which a system is susceptible to and unable to cope with adverse effects of climate change including climate variability and extremes' (IPCC, 2007:16). According to O'Donoghue, Shava and Zazu (2014:36), indigenous knowledge serves as 'a source of local community resilience that provides an enabling capacity for people to sustain their livelihoods and adapt to environmental changes or new environments'. The most important measures for implementing IKS will be to increase the use of renewable energy, and to encourage reforestation while halting the rate of deforestation.

\section{Theme 3: IKS and the knowledge of indigenous plants}

The participants related that they possess knowledge of the diversity of plants and animals for medicinal purposes: 'Re le dingaka tša setšo rena le tsebo ya go fapana ka dihlare le diphoofolo tša naga tšeo ka moka re di šomišago go alafa balwetsi'; and that, 'due to our role as traditional healers and indigenous knowledge holders', they are able to treat their fellow community members: 'Re šomiša dihlare tša hlago go alafa malwetši ao a sa tlwaelegago' [They use herbs to treat common ailments].

Inspite of the fact that these local indigenous communities depend on these plants, they are often excluded from the management of these resources.

\section{Discussion and recommendations}

The findings suggest that indigenous knowledge holders are already using their knowledge for their livelihoods under difficult circumstances (little rain, high temperatures, no electricity or 
running water, and dwindling resources such as trees). Some community members even have the knowledge to use plants for healing. Such holders of specialised knowledge can be powerful agents of change in efforts aimed at environmental sustainability. Holders of special indigenous knowledge often play a leading role in the community, and, by sharing their intellectual and social capital, could assist in the protection and management of natural resources.

Currently, communities feel vulnerable to prosecution for over-harvesting trees for fuel. However, IKS could be a practical tool that would allow state authorities to develop indigenousresponsive environmental policies and coping strategies.

The study confirmed that indigenous communities are vulnerable, not only to climate challenges but to the unequal distribution of land and resources such as water and energy. It suggests that their participation in environmental sustainability initiatives is critical; and, indeed, the participants in this study were concerned that their knowledge and experiences were not being taken into account by the government. It is ironic that the democratically elected government that replaced the colonial and apartheid governments still chooses to ignore people's indigenous knowledge.

The inclusion of indigenous knowledge in decision-making can help or hinder strategies related to energy use and deforestation, or water and medicinal plant conservation, among other activities. Forging a negotiated approach for natural resource management - one that takes into account what people say, know and experience - could promote natural resource custodianship and thus greater resilience among indigenous communities. As such, they should be afforded the opportunity to participate in addressing environmental challenges such as climate change and dwindling resources. This could be done by facilitating feedback, debate and a sense of partnership in educational activities and governance.

This paper's main contention is that education in both the environmental and social work fields which incorporates the kinds of IKS described in this paper can work together to address social-ecological concerns which impact the environment, human rights, development opportunities and health of the most vulnerable members of society. Social workers who work in marginalised communities need to appropriately engage with issues pertaining to environmental risk, livelihoods and IKS in order to help families and communities cope with life's stresses and shocks.

The Afro-sensed approach (Masoga \& Kaya, 2011:153) contends that 'communities cannot significantly advance in the development of Africa unless those involved in the development process of the continent take African societies and cultures seriously'. In line with the sustainable livelihood approach, local experts should strengthen local capabilities in disaster risk management, traditional agriculture and climatic knowledge by consolidating and spreading IKS through their knowledge and practice.

\section{Notes on the contributors}

\section{Lead author}

Masoga, Mogomme Alpheus | Faculty of Arts, University of Zululand, South Africa

ORCID: 0000-0002-3335-3633 | Alpheus.Masoga@ul.ac.za 
Professor Masoga is Dean of Arts at the University of Zululand. His research interests include Afrikology, cultural history, indigenous knowledge systems, social entrepreneurship and decoloniality studies.

\section{Co-author}

Shokane, Allucia Lulu | Department of Social Work, University of Venda, South Africa

ORCID: 0000-0002-2928-1526

Dr Shokane is a senior lecturer in the Department of Social Work at the University of Venda. Her research interests are in social work studies, women's empowerment, community development and indigenous knowledge systems.

\section{Percentage contribution}

\begin{tabular}{|l|l|l|}
\hline Areas of contribution & Authors & $\begin{array}{l}\text { Percentage } \\
\text { contribution }\end{array}$ \\
\hline \multirow{2}{*}{$\begin{array}{l}\text { Conception or design of the paper, theory } \\
\text { or key argument }\end{array}$} & Masoga & $50 \%$ \\
\cline { 2 - 3 } & Shokane & $50 \%$ \\
\hline \multirow{2}{*}{ Data collection } & Masoga & $50 \%$ \\
\cline { 2 - 3 } & Shokane & $50 \%$ \\
\hline \multirow{2}{*}{ Analysis and interpretation } & Masoga & $50 \%$ \\
\hline \multirow{2}{*}{ Drafting the paper } & Shokane & $50 \%$ \\
\hline \multirow{2}{*}{ Critical review of paper } & Masoga & $50 \%$ \\
\cline { 2 - 3 } & Shokane & $50 \%$ \\
\hline & Masoga & $50 \%$ \\
\cline { 2 - 3 } & Shokane & $50 \%$ \\
\hline
\end{tabular}

\section{References}

Asante, M.K. (1998). The Afrocentric idea. Philadelphia, PA:Temple University Press.

Babbie, E. \& Mouton, J. (2001). The practice of social research. Cape Town: Oxford University Press.

Chambers, R. \& Conway, G. (1992). Sustainable rural livelihoods: Practical concepts for the 21st century. IDS Discussion Paper 296. Brighton: IDS.

Dominelli, L. (2011). Climate change: Social workers' roles and contribution to policy debates and interventions. International Journal of Social Welfare, 20(4), 430-438.

Dominelli, L. (2012). Green social work. Cambridge: Polity Press.

Gray, M., Coates, J. \& Hetherington, T. (Eds). (2013). Environmental social work. Abingdon: Routledge.

Hsieh, H.-F. \& Shannon, S.E. (2005). Three approaches to qualitative content analysis. Qualitative Health Research, 15(9), 1277-1288. 
IFSW (International Federation of Social Workers), IASSW (International Association of Social Workers) (IASSW) \& ICSW (International Council on Social Welfare). (2012). The Global Agenda for Social Work and Social Development: Commitment to Action. Berne: IFSW.

IPCC (Intergovernmental Panel on Climate Change). (2007). Summary for policymakers. In S. Solomon, D. Qin, M. Manning, Z. Chen, M. Marquis, K.B. Averyt, M. Tignor \& H.L. Miller (Eds), Climate change 2007: The physical science basis. Contribution of Working Group I to the Fourth Assessment Report of the Intergovernmental Panel on Climate Change. Cambridge and New York, NY: Cambridge University Press. Retrieved from https://www.ipcc.ch/ report/ar4/wg1/ [accessed 7 May 2019].

Jones, D.N. \& Truell, R. (2012). The global agenda for social work and social development: A place to link together and be effective in a globalised world. International Social Work, 55(4), 454-472.

Kalu, O. (2008). African Pentecostalism: An introduction. Oxford: Oxford University Press.

Lysack, M. (2008). Global warming as a moral issue: Ethics and economics of reducing carbon emissions. Interdisciplinary Environmental Review, 10(1/2), 95-109.

Magoro, M.D. \& Masoga, M.A. (2005). Aspects of indigenous knowledge and protection in small-scale farming systems: A challenge for advancement. Indilinga: African Journal of Indigenous Knowledge Systems, 4(1), 414-428.

Masoga, M.A. (2017). Critical reflections on selected local narratives of contextual South African indigenous knowledge. In P. Ngulube (Ed.), Handbook of research on theoretical perspectives on indigenous knowledge systems in developing countries (pp. 310-331). Hershey, PA: IGI Global.

Masoga, M.A \& Kaya, H. (2011). Building on the indigenous: An appropriate paradigm for sustainable development in Africa. In G. Walmsley (Ed.), African philosophy and the future of Africa (p. 153). Washington, DC: Council for Research in Values and Philosophy.

Masoga, M.A. \& Shokane A.L. (2018). Towards an integration of indigenous knowledge and social work strategies in coping with climate change: An Afro-sensed approach. In M. Rinkel \& M.C.F. Powers (Eds), Social work promoting community and environmental sustainability: A workbook for global social workers and educators (pp. 93-104). Berne: International Federation of Social Workers (IFSW).

Mokuku, T. \& Janse van Rensburg, E. (1997). Reflecting on socially transformative environmental literacy for Lesotho. Southern African Journal of Environmental Education, 17, 31-39.

Muchenje, F. \& Goronga, P. (2015). Developing strategies for the promotion of indigenous knowledge systems in Africa's development: A Perspective from the South. International Journal of Social Science E Education, 5(4), 538-546.

Mwansa, L. (2011). Social work education in Africa:Whence and whither? Social Work Education, 30(1), 4-16.

Mwansa, L.J. (2010). Challenges facing social work education in Africa. International Social Work, 53(1): 129-136.

O’Donoghue, R., Shava, S. \& Zazu, C. (Eds). (2014). African heritage knowledge in the context of social innovation. Yokohama: United Nations University Institute of Advanced Studies (UNUIAS). 
Prah, K. (2016). Thinking African: Reflections on indigenous knowledge and development. Presentation at the Annual School of Human and Social Sciences Lecture Series, 16-18 May 2016, University of Venda, South Africa.

Reddy, C. (2017). Environmental education in teacher education: A viewpoint exploring options in South Africa. Southern African Journal of Environmental Education, 33, 117-126.

Rinkel, M. \& Powers, M.C.F. (Eds). (2018). Social work promoting community and environmental sustainability: A workbook for global social workers and educators. Berne: International Federation of Social Workers (IFSW).

Shava, S. \& Manyike, T.V. (2018). Decolonial role of African indigenous language. Indilinga: African Journal of Indigenous Knowledge Systems, 17(1), 36-52.

Shava, S., Zazu, C., Tidball, K. \& O’Donoghue, R. (2009). Local knowledge as a source of community resilience. Indilinga: African Journal of Indigenous Knowledge Systems, 8(2), 218-229.

Shava, S. (2013). The representation of indigenous knowledges. In R.B. Stevenson, M. Brody, J. Dillon $\&$ A. Wals (Eds), International handbook of research on environmental education. New York, NY: Routledge.

Shava, S. (1999). The use of indigenous plants as food by a rural community in the Eastern Cape: Tuku 'a' village, Peddie. Southern African Journal of Environmental Education, 19, 85-97.

Shokane A.L \& Nel, H. (2017). Community development intervention guidelines for communities affected by natural disasters. In M. Rinkel \& M.C.F. Powers (Eds), Social work promoting community and environmental sustainability: A workbook for global social workers and educators (pp 107-120). Berne: International Federation of Social Workers (IFSW).

Shokane, A.L. (2016). Indigenous knowledge and social work in the context of climate change and older persons in rural areas. Indilinga: African Journal of Indigenous Knowledge Systems, 15(2), 105-122.

UNDP (United Nations Development Programme). (2007). Fighting climate change: Human solidarity in a divided world. Human Development Report 2007/2008. New York, NY: UNDP.

Zuber-Skerrit, O. \& Fletcher, M. (2007). The quality of an action research thesis in the social sciences. Quality Assurance in Education, 15(4), 413-436. 